PIWOWARCZYK R. 2012. Orobanche alba subsp. alba and subsp. major (Orobanchaceae) in Poland: current distribution, taxonomy, plant communities, hosts, and seed micromorphology. - Biodiversity: Research and Conservation 26: 23-38.

PoŻARYSKI W. 1948. Jura i kreda między Radomiem, Zawichostem i Kraśnikiem. - Biuletyn Instytutu Geologicznego 46: 5-141.

RozPorZĄDZENIE Ministra Środowiska z dnia 9 października 2014 r. w sprawie ochrony gatunkowej roślin (Dz. U. z 2014 r., poz. 1409).

Solon J., Borzyszkowski J., Bidłasik M., Richling A., Badora K.. Balon J., Brzezińska-Wójcik T. Chabudziński Ł., Dobrowolski R., Grzegorczyk I., JodŁowski M., Kistowski M., Kot R., Krąż P. Lechnio J., Macias A., Majchrowska A., Malinowska E., Migoń P., Myga-Piątek U., Nita J., Papińska E., RodZik J., StrzyŻ M., TerpiŁowski S. \& Ziaja W. 2018. Physico-geographical mesoregions of Poland: verification and adjustment of boundaries on the basis of contemporary spatial data. - Geographia Polonica 91(2): 143-170.

WALASZCZYK I. 2004. Inoceramids and inoceramid biostratigraphy of the Upper Campanian to basal Maastrichtian of the Middle Vistula River Section, central Poland. - Acta Geologica Polonica 54: 95-168.

ZAJĄC A. \& ZAJĄC M. (red.). 2001. Atlas rozmieszczenia roślin naczyniowych w Polsce. s. xii + 714. Pracownia Chorologii Komputerowej Instytutu Botaniki Uniwersytetu Jagiellońskiego, Kraków.

ZAJĄC A. 1978. Założenia metodyczne „Atlasu rozmieszczenia roślin naczyniowych Polski”. - Wiadomości Botaniczne 22(3): 145-155.

Pawee Pawlikowski, Zakład Ekologii i Ochrony Środowiska, Wydział Biologii, Instytut Biologii Środowiskowej, Uniwersytet Warszawski, ul. Żwirki i Wigury 101, 02-089 Warszawa, Polska; e-mail:p.pawlikowski@uw.edu.pl

Iwona Dembicz, Zaktad Ekologii i Ochrony Środowiska, Wydział Biologii, Instytut Biologii Środowiskowej, Uniwersytet Warszawski, ul. Żwirki i Wigury 101, 02-089 Warszawa, Polska; e-mail: i.dembicz@biol.uw.edu.pl

ŁukAsz KozuB, Zakład Ekologii i Ochrony Środowiska, Wydziat Biologii, Instytut Biologii Środowiskowej, Uniwersytet Warszawski, ul. Żwirki i Wigury 101, 02-089 Warszawa, Polska; e-mail:lukasz.kozub@biol.uw.edu.pl

Magdalena Galus, Centrum Ochrony Mokradet, ul. Żwirki i Wigury 101 lok. 1.135, 02-089 Warszawa, Polska; e-mail: m.galus@bagna.pl

Wptynęto: 30.10 .2019 r.; przyjęto do druku: 30.11 .2020 r.

DOI: https://doi.org/10.35535/ffgp-2020-0052

\title{
Synantropijne stanowisko Plantago maritima (Plantaginaceae) na autostradzie A4 w Gliwicach (Górny Śląsk)
}

Plantago maritima L., babka nadmorska, jest obligatoryjnym halofitem rosnącym przede wszystkim na wybrzeżach oraz dużo rzadziej na stanowiskach śródlądowych. Jej zasięg obejmuje większość wybrzeży północnej, zachodniej i południowej Europy, zachodnią i centralną Azję, północno-zachodnią Afrykę, północne i środkowe wybrzeża Ameryki 
Północnej oraz południowe rejony Ameryki Południowej (Chile, Argentyna) (Meusel i in. 1978; Hultén \& Fries 1986; Meusel \& JäGer 1992; Plants of the World Online).

Babka nadmorska jest gatunkiem zróżnicowanym na kilka niższych jednostek taksonomicznych. W Europie, w zależności od ujęcia, wyróżnia się trzy (CHATER \& CARTIER 1976), cztery (Meusel i in. 1978; CHRTEK sen. 2000), a nawet, według najnowszych podziałów, sześć podgatunków (MARHOLD 2011). W Polsce do tej pory rozpoznane zostały dwa taksony: typowy - rodzimy i rosnący na większości znanych stanowisk oraz subsp. serpentina (All.) Arcang. - sprowadzony z Alp na przełomie XIX i XX w. i zadomowiony na Hali Stoły w Tatrach (MireK i in. 2002). Osobniki na nowo znalezionym stanowisku charakteryzują się obecnością pojedynczych rzęsek na brzegu łatek korony, co wskazuje, że jest to występujący m.in. w Republice Czeskiej podgatunek subsp. ciliata Printz. (KAPLAN i in. 2018; PlaDIAS). Obecność rozproszonego orzęsienia na brzegach łatek korony jest wymieniane jako zasadnicza cecha wyróżniająca ten takson (TACIK 1967; CHRTEK sen. 2000). Warto dodać, że podgatunek subsp. ciliata rozprzestrzenia się wzdłuż dróg szybkiego ruchu u naszego południowego sąsiada (KAPLAN i in. 2018).

Notowana do tej pory w Polsce Plantago maritima s. str. jest gatunkiem rzadkim, narażonym na wyginięcie (kategoria VU) (SOTEK i in. 2014; KAźMIERCZAKOwA i in. 2016) oraz podlegającym ścisłej ochronie gatunkowej i wymagającym ochrony czynnej (RozPORZĄDZENIE 2014). Spotykana jest wzdłuż wybrzeża Morza Bałtyckiego, skąd znanych było 50 stanowisk zlokalizowanych w 30 jednostkach kartogramu ATPOL (ZAJĄC \& ZAJĄC 2001; LAZARUS \& WSZAŁEK-RoŻEK 2016). Przeprowadzona w 2013 r. inwentaryzacja stanowisk nadmorskich (LAZARUS \& WSZAŁEK-RoŻEK 2016) wykazała istnienie zaledwie $18 \mathrm{z}$ nich. Babka nadmorska rośnie tu głównie na wilgotnych łąkach i pastwiskach, w zagłębieniach między wydmami oraz w innych naturalnych i półnaturalnych siedliskach zasilanych wodą morską lub słonymi wodami podziemnymi. Sporadycznie znajdowana była również na kamiennych umocnieniach brzegów (falochronach) (SOTEK i in. 2014; LAZARUS \& WSZAŁEK-RoŻEK 2016). W XIX w. podano również dwa stanowiska śródlądowe, które później nie zostały potwierdzone, a przez niektórych autorów uważane są za wątpliwe (Wilkoń-Michalska 1963; Piotrowska 1988, 1993, 2001; Zając \& ZająC 2001; SoteK $\mathrm{i}$ in. 2014). W Atlasie rozmieszczenia roślin naczyniowych w Polsce (ZAJĄC \& ZAJAc 2001) została zawarta informacja o jeszcze jednym wątpliwym stanowisku, zlokalizowanym w jednostce AD kartogramu ATPOL. Lokalizacja ta nie została wymieniona w późniejszych, opartych również o dane ATPOL, opracowaniach zamieszczonych w dwóch wydaniach Polskiej czerwonej księgi roślin (Piotrowska 2001; Sotek i in. 2014). Niestety, na podstawie cytowanej w Atlasie literatury (PIOTROwSKA 1988, 1993) autorom nie udało się dotrzeć do dodatkowych informacji o tym stanowisku. W bazie danych ATPOL (A. Zając, inf. ustna z 2020 r.) widnieje ono pod zapisem „Cybinka”, a jako źródło podano materiały publikowane Eugeniusza Ćwiklińskiego z 1989 r. Pomimo dalszych poszukiwań nie udało się wyjaśnić z jakiej publikacji pochodzi podana informacja, stąd, wzorem innych autorów, postanowiono nie zaznaczać tego stanowiska na mapie rozmieszczenia $P$. maritima w Polsce (Ryc. 1).

W związku z posypywaniem dróg solą przemysłową, w celu zapobiegania ich oblodzeniu, od kilku dziesięcioleci obserwowane jest zjawisko rozprzestrzeniania się rodzimych 


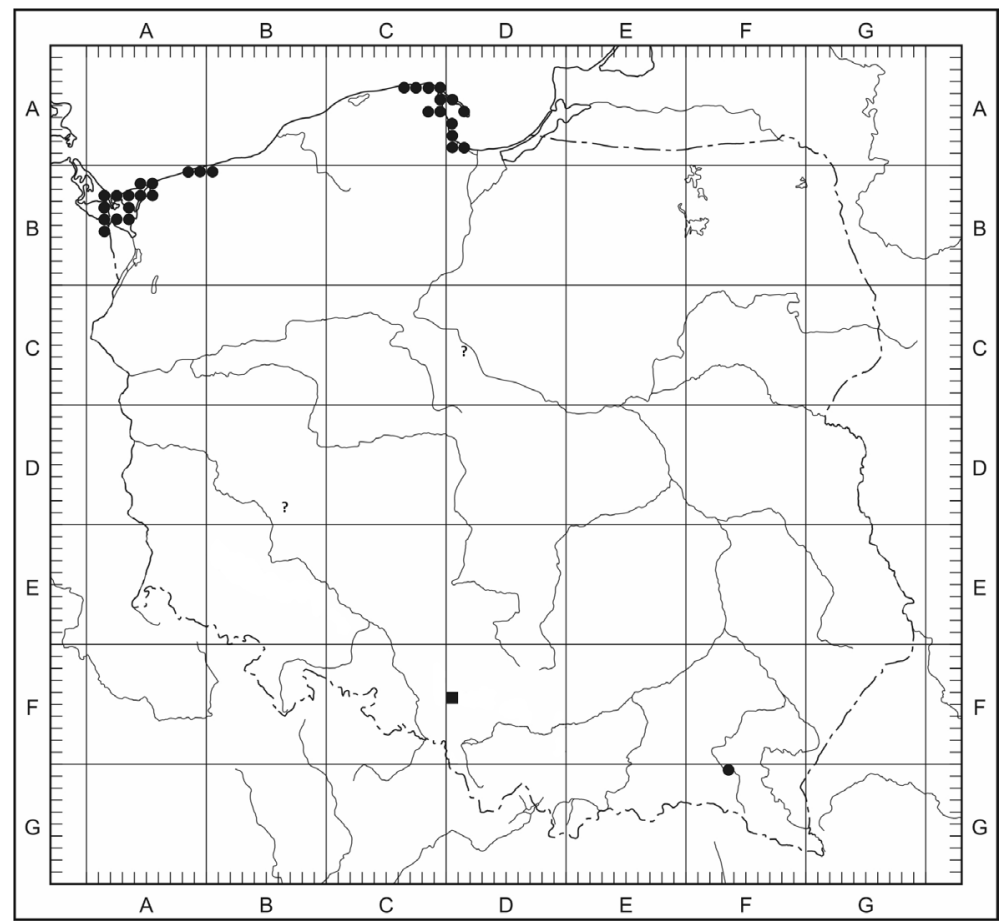

Ryc. 1. Mapa rozmieszczenia Plantago maritima w Polsce, przy użyciu siatki kartogramu ATPOL (ZAJĄC \& ZAJĄC 2001, zmienione): - - nowe stanowisko; • - stanowiska publikowane; ? - stanowiska wątpliwe

Fig. 1. Distribution map of Plantago maritima in Poland, using the ATPOL cartogram grid (ZAJAC \& ZAJAC 2001, modified): - - new locality; • - published localities; ? - uncertain localities

halofitów wzdłuż szlaków komunikacyjnych. W Polsce na tego typu antropogenicznych siedliskach notowane były m.in. Puccinellia distans (MireK \& TrZCiŃsKA-TACIK 1981; Wróbel i in. 2006; ZAJAc \& Zają 2019), Plantago coronopus (SADOwsKa \& ŻóŁKoś 2011; SOTEK 2014; ZAJĄC \& ZAJĄC 2019) oraz Spergularia marina (NoBIS 2007; PlisZKO 2017; ZAJĄC \& ZAJĄC 2019). Plantago maritima na poboczach dróg notowana była od dawna na terenie Europy, m.in. w Wielkiej Brytanii (MATthews \& DAvison 1976; ScotT \& Davison 1982, 1985), w Niemczech (Friese 2011; Diewald i in. 2017), na Węgrzech (BARINA 2007) oraz w Republice Czeskiej (KAPLAN i in. 2018), natomiast z Polski do tej pory znane było jedno stanowisko, odnalezione na poboczu drogi krajowej nr 9 na obszarze Dołów Jasielsko-Sanockich (JAźwA \& PiąTeK 2015).

Nowe synantropijne stanowisko babki nadmorskiej zostało znalezione w 2014 r. na autostradzie A4 przy dojeździe od strony wschodniej do Punktu Poboru Opłat Żernica w południowej części Gliwic $\left(50^{\circ} 15^{\prime} 32,1^{\prime \prime} \mathrm{N}, 18^{\circ} 40^{\prime} 43,7^{\prime \prime} \mathrm{E}\right.$; ATPOL: DF 40) (Ryc. 1). Stanowisko to było obserwowane również w kolejnych latach, ostatnio w 2020 r. Przynajmniej kilkadziesiąt kęp babki nadmorskiej rośnie przy końcu pasa zieleni oddzielającego jezdnie. Roślina ta została zauważona przypadkowo, podczas przymusowego postoju w zatorze, który dość często tworzy się w tym miejscu. Niestety specyfika stanowiska uniemożliwia zebranie dokładniejszych danych o liczebności oraz siedlisku tego gatunku. 
Razem z Plantago maritima rosła Spergularia marina oraz P. coronopus, co sugeruje, że w tym miejscu mogą występować również inne ciekawe gatunki tolerujące wysokie zasolenie gleby.

Summary. Synanthropic locality of Plantago maritima (Plantaginaceae) on the A4 highway in Gliwice (Silesia Province). Plantago maritima is a rare and endangered species in Poland. It grows mainly in saline natural and semi-natural communities along the Baltic Sea coast. There are 50 known localities of the species in this area, located in 30 units of the ATPOL cartogram. Until now, one synanthropic locality situated on roadside in the Jasło-Sanok Basin was known. A new synanthropic locality of $P$. maritima was found in 2014 on the A4 motorway next to the Żernica Toll Point in the southern part of Gliwice $\left(18^{\circ} 40^{\prime} 43,7^{\prime \prime} \mathrm{E}, 50^{\circ} 15^{\prime} 32,1^{\prime \prime} \mathrm{N}\right.$; ATPOL DF 40) (Fig. 1). At least several dozen individuals were observed in the center strip, together with Spergularia marina and Plantago coronopus. The presence of single cilia on the edge of the corolla patches suggests that the taxon represents $P$. maritima subsp. ciliata. It occurs in the Czech Republic, where it spreads along motorways.

\section{LITERATURA}

BARINA Z. 2007. A Vértes és környéke florisztikai kutatásának eredményei I. - Kitaibelia 12: 30-40.

Chater A. O. \& Cartier D. 1976. Plantago L. - W: T. G. Tutin, V. H. Heywood, N. A. Burges, D. M. Moore, D. H. Valentine, S. M. Walters \& D. A. Webb (red.), Flora Europaea. 4. Plantaginaceae to Compositae (and Rubiaceae), s. 38-44. Cambridge University Press, Cambridge.

Chrtek J. sen. 2000. Plantaginaceae Juss. - jitrocelovité. - W: B. Slavík, J. ChrTEK jun. \& J. ŠTĚPÁnKová (red.), Květena České republiky. 6, s. 529-549. Academia, Praha.

Diewald W., Gregor T., Hohla M., Nawrath S. \& Király G. 2017. Plantago maritima subsp. maritima, ein Neubürger an ostbayerischen Fernstraßen. - Hoppea, Denkschriften der Regensburgischen Botanischen Gesellschaft 78: 111-116.

FrIESE M. 2011. Einzug der Halophyten. Florenwandel an der Autobahn A4 im Bautzener Hügelland. Berichte der Naturforschenden Gesellschaft der Oberlausitz 19: 79-84.

Hultén E. \& Fries M. 1986. Atlas of North European vascular plants north of the Tropic of Cancer. s. 1172. Koeltz Scientific Books, Königstein.

JAŹwa M. \& PiąTeK K. 2015. Nowe stanowiska rzadkich roślin naczyniowych na Pogórzu Ciężkowickim, Pogórzu Strzyżowskim i w Dołach Jasielsko-Sanockich (Karpaty Zachodnie). - Fragmenta Floristica et Geobotanica Polonica 22(1): 100-103.

Kaplan Z., Koutecký P., Danihelka J., ŠUmberová K., DucháČEK M., ŠTĚPÁnková J., Ekrt L., GruLich V., Řepka R., Kubát K., Mráz P., Wild J. \& BRŮNa J. 2018. Distributions of vascular plants in the Czech Republic. Part 6. - Preslia 90: 235-346.

Kaźmierczakowa R., Bloch-OrŁowska J., Celka Z., Cwener A., Dajdok Z., Michalska-Hejduk D., Pawlikowski P., SzCZÉ́śniaK E. \& ZiarneK K. 2016. Polska czerwona lista paprotników i roślin kwiatowych. s. 44. Instytut Ochrony Przyrody Polskiej Akademii Nauk, Kraków.

LaZarus M. \& WszaŁeK-RożeK K. 2016. Two rare halophyte species: Aster tripolium L. and Plantago maritima L. on the Baltic coast in Poland - their resources, distribution and implications for conservation management. - Biodiversity: Research and Conservation 41: 51-60.

MARHOLD K. 2011. Plantago. - W: Euro+Med Plantbase - the information resource for Euro-Mediterranean plant diversity. http://ww2.bgbm.org/EuroPlusMed/PTaxonDetail.asp?NameCache=Plantago\%20 maritima\&PTRefFk=7200000 (dostęp: 04.10.2020).

Matthews P. \& Davison A. W. 1976. Maritime species on roadside verges. - Watsonia 11: 146-147. 
Meusel H. \& JÄGER E.1992. Vergleichende chorologie der Zentraleuropäischen Flora. 2, s. 422-688. G. Fischer Verl., Jena - Stuttgart - New York.

Meusel H., Jäger E., Rauschert S. \& Weinert E. 1978. Vergleichende chorologie der Zentraleuropäischen Flora. 3, s. 259-421. G. Fischer Verl., Jena - Stuttgart - New York.

Mirek Z., Pięroś-Mirkowa H., ZaJąC A. \& ZająC M. 2002. Flowering plants and pteridophytes of Poland. A checklist. - W: Z. MireK (red.), Biodiversity of Poland. 1, s. 442. W. Szafer Institute of Botany, Polish Academy of Sciences, Kraków.

Mirek Z. \& Trzcińska-Tacik H. 1981. Spreading of Puccinellia distans (L.) Parl. along the roads in southern Poland. - Ekologia Polska 92: 345-352.

NobIS M. 2007. Rośliny naczyniowe zachodniej części Przedgórza Iłżeckiego (Wyżyna Małopolska). - Prace Botaniczne 44: 1-458.

Piotrowska H. 1988. Plantago maritima L. - W: A. Jasiewicz (red.), Materiały do poznania gatunków rzadkich i zagrożonych Polski. Cz. I. - Fragmenta Floristica et Geobotanica 33(3-4): 454-464.

Piotrowska H. 1993. Plantago maritima L. - babka nadmorska. - W: K. ZARZYCKI \& R. KAŹMIERCZAKOWA (red.), Polska czerwona księga roślin. Paprotniki i rośliny kwiatowe, s. 171-172. Instytut Botaniki im. W. Szafera PAN, Instytut Ochrony Przyrody PAN, Kraków.

Piotrowska H. 2001. Plantago maritima L. Babka nadmorska. - W: R. KAŹMIERCZAKOwa \& K. ZARZYCKI (red.), Polska czerwona księga roślin. Paprotniki i rośliny kwiatowe, s. 347-348. Instytut Botaniki im. W. Szafera PAN, Instytut Ochrony Przyrody PAN, Kraków.

Pladias. Databáze české flóry a vegetace. http://pladias.cz (dostęp: 04.10.2020).

Plants of the World Online. Kew Royal Botanic Gardens. Kew Science. http://powo.science.kew.org/ taxon/urn:lsid:ipni.org:names:30063012-2 (dostęp: 04.10.2020).

PliszKo A. 2017. A new record of Spergularia marina (Caryophyllaceae) from southern Poland. - Acta Musei Silesiae: Scientiae Naturales 66: 49-51.

RozPorZĄDZENIE Ministra Środowiska z dnia 9 października 2014 r. w sprawie ochrony gatunkowej roślin (Dz. U. 2014, poz. 1409).

SAdowska Z. \& ŻóŁKoś K. 2011. Antropogeniczne stanowisko babki pierzastej Plantago coronopus L. w Gdańsku. - Acta Botanica Cassubica, Monographiae 10: 107-114.

Scott N. E. \& Davison A. W. 1982. De-icing salt and the invasion of road verges by maritime plants. - Watsonia 14: 41-52.

Scott N. E. \& Davison A. W. 1985. The distribution and ecology of coastal species on roadsides. - Vegetatio 62: 433-440.

SoteK Z. 2014. Plantago coronopus L. Babka pierzasta. - W: R. KAŹMIERCZAKowa, K. ZARZYCKI \& Z. MireK (red.), Polska czerwona księga roślin. Paprotniki i rośliny kwiatowe, s. 485-487. Instytut Ochrony Przyrody PAN, Kraków.

Sotek Z., Prajs B. \& BiaŁecka B. 2014. Plantago maritima L. Babka nadmorska. - W: R. KaźmiercZAKowa, K. ZARZYCKI \& Z. MireK (red.), Polska czerwona księga roślin. Paprotniki i rośliny kwiatowe, s. 487-489. Instytut Ochrony Przyrody PAN, Kraków.

TACIK T. 1967. Plantaginaceae, Babkowate. - W: B. PAwŁowski (red.), Flora Polska. Rośliny naczyniowe Polski i ziem ościennych. 11, s. 237-256. Państwowe Wydawnictwo Naukowe, Warszawa - Kraków.

WilkoŃ-MichalsKa J. 1963. Halofity Kujaw. - Studia Societatis Scientiarum Torunensis, Sectio D 7(1): $1-122$.

Wróbel M., Tomaszewicz T. \& ChudecKa J. 2006. Floristic diversity and spatial distribution of roadside halophytes along forest and field roads in Szczecin Lowland (West Poland). - Polish Journal of Ecology 54(2): 303-309. 
ZAJĄC A. \& ZAJĄC M. (red.). 2001. Atlas rozmieszczenia roślin naczyniowych w Polsce. s. xii + 714. Nakładem Pracowni Chorologii Komputerowej Instytutu Botaniki Uniwersytetu Jagiellońskiego, Kraków.

ZAJĄC A. \& ZAJĄC M. (red.). 2019. Atlas rozmieszczenia roślin naczyniowych w Polsce: dodatek. s. 319. Instytut Botaniki Uniwersytetu Jagiellońskiego, Kraków.

KATARZYNA KOZŁOWSKA-KOZAK (autor korespondencyjny), e-mail: katarzyna.kozlowska2@ gmail.com

MACIEJ KoZAK, e-mail: maciejkozak1@tlen.pl

Wptynęto: 17.05.2020 r.; przyjęto do druku: 15.12.2020 r.

DOI: https://doi.org/10.35535/ffgp-2020-0053

\section{Efemerycziny pojaw Ambrosia artemisiifolia (Asteraceae) w Warszawie}

Ambrosia artemisiifolia L. (ambrozja bylicolistna) jest okazałym terofitem z rodziny Asteraceae, pochodzącym z południowego-wschodu USA, ustawowo zwalczanym na obszarze Wspólnoty Europejskiej, Federacji Rosyjskiej, Chin oraz Indii (Allard 1943; Li \& Li 1993; Duan \& Chen 2000; Moskalenko 2001; Alberternst i in. 2006, Protopopova i in. 2006; Guo i in. 2011). Roślina będąc źródłem bardzo silnego alergenu pyłkowego oraz uporczywym chwastem soi w klimacie ciepłym i suchym, powoduje na terenie Unii Europejskiej straty rzędu 4,5 miliarda euro rocznie (KASPRZYK i in. 2011; BULLOCK i in. 2012; BLACKBURN i in. 2014). Rozprzestrzenia się także w innych regionach świata, od Alaski i Syberii na północy po strefę międzyzwrotnikową (BÉREs 2003). Ambrosia artemisiifolia jest uważana za jeden z najbardziej szkodliwych chwastów na terenie Europy, jednak jej wpływ na naturalne ekosystemy nie został jeszcze wystarczająco zbadany (BzDĘGA i in. 2018a).

Do Polski gatunek trafił w XVIII lub XIX w. Na terenie kraju uznano go za regionalnie inwazyjny (ToKARSKA-GuZIK i in. 2012). Źródłem inwazji są jednonasienne owoce, produkowane w ogromnej ilości. Na siedliskach ruderalnych roślina zazwyczaj wygrywa konkurencję z gatunkami rodzimymi, przede wszystkim ze względu na zdolność kolonizowania nagiej gleby oraz dzięki bardzo szybkiemu kiełkowaniu i rozwojowi (BzDEGA $\mathrm{i}$ in. 2018b). Ambrozja bylicolistna zadomawia się głównie na południowym zachodzie kraju, ale pozostaje rzadsza niż w pannońskim i pontyjskim obszarze biogeograficznym Ukrainy, Czech, Słowacji, Austrii oraz Węgier (Csontos i in. 2010; ToKARskA-GuzIK $\mathrm{i}$ in. 2011, 2012).

Pomimo tego, że stanowiska Ambrosia artemisiifolia koncentrują się głównie w południowej części Polski (ZAJĄC \& ZAJĄC 2019; http://geoserwis.gdos.gov.pl/mapy/), została ona uznana za bardzo inwazyjny gatunek obcy (BZDĘGA i in. 2018b). W Warszawie tego kenofita obserwowano tylko kilka razy, a opublikowano jedynie obserwację z końca lat 80. minionego stulecia (SUDNIK-WóJCIKOWSKA 1987a, b). Na bocznicy przy młynie w Białołęce 